\title{
INTEGRASI TEORI RUANG TERBUKA HIJAU DAN TEORI REKREASI UNTUK ANALISA FUNGSI SOSIAL TERHADAP TAMAN KOTA DI KOTA SURAKARTA
}

\author{
Prasetyo Febriarto ${ }^{1}$ \\ ${ }^{1}$ Jurusan Sipil dan Perencanaan STIMK AMIKOM, Yogyakarta
}

\begin{abstract}
ABSTRAK
Tujuan dari penelitian ini adalah untuk mengetahui fungsi sosial dengan adanya keberadaan taman kota di Kota Surakarta. Obyek kajian ini adalah fungsi sosial di empat Taman Kota di Kota Surakarta yaitu, Taman Balekambang, Taman Tirtonadi, Taman Banjarsari dan Taman Sekartaji. Metode analisis yang digunakan dalam penelitian ini menggunakan analisis deskriptif eksploratif. Dilakukan dengan cara menganalisis fungsi sosial terhadap keberadaan taman kota. Analisa kegiatan aktivitas yang terjadi di luar dan di dalam taman kota. Penelitian dilakukan untuk mengetahui fungsi sosial yang terjadi untuk menunjukkan taman kota yang berkualitas baik dan ideal dari empat taman kota tersebut..
\end{abstract}

Kata kunci : fungsi sosial, ruang terbuka hijau, taman kota publik

\begin{abstract}
The purpose of this study is to determine the social function with the existence of the city park in the city of Surakarta. The object of this study is the social function of four urban parks in Surakarta city, Balekambang Park, Tirtonadi Park, Banjarsari Park and Sekartaji Park. The method of analysis used in this study using descriptive explorative analysis. Done by analyzing the social function of the existence of the city park. Analyze activity activities that occur outside and inside the city park. The study was conducted to determine the social function that occurs to show the city parks of good quality and ideal of the four city parks.
\end{abstract}

Keywords : green open spaces, public city park, social function

\section{PENDAHUUAN}

Berdasarkan Permendagri nomor 1 tahun 2007, Ruang Terbuka Hijau Kawasan Perkotaan yang selanjutnya disingkat RTHKP adalah bagian dari ruang terbuka suatu kawasan perkotaan yang diisi oleh tumbuhan dan tanaman guna mendukung manfaat ekologi, sosial, budaya, ekonomi dan estetika.

Menurut Beer, AR (2003) dalam Hakim, 2014:25,Taman kota menjadi area rekreasi dan istirahat ke penghuni kota dan ruang terbuka hijau sangat penting dalam menjaga keanekaragaman kehidupan di dalam kota, menjaga kualitas udara dan suhu kota serta kualitas air. Berdasarkan Permen PU No.05/PRT/M/2008, menyatakan Taman Kota adalah lahan terbuka yang berfungsi sosial dan estetik sebagai sarana kegiatan rekreatif, edukasi atau kegiatan lain pada tingkat kota.

Ruang Terbuka Hijau (RTH) berupa taman kota yang ada di Kota Surakarta yang berada di pusat kegiatan antara lain Taman Monumen 45 (Taman Monjari), Taman Sekartaji di pinggir Sungai Pepe, Taman Tirtonadi di pinggir Sungai Pepe, Taman Balekambang. Keberadaan taman kota dapat menciptakan kondisi kota yang indah, sejuk dan nyaman serta menunjukan sebuah kota yang baik dan ideal. Salah satu fungsi taman kota sebagai fungsi sosial yang berkaitan erat dengan aktivitas rekreasi pengguna sangat penting untuk mengetahui aktivitas apa saja yag terjadi di taman kota.

Permasalahannya yaitu kondisi eksisting taman kota publik yang berhubungan fungsi sosial dan kondisi baik, ideal dan tidaknya dari empat taman kota. Pertanyaan penelitian sebagai berikut:

1. Bagaimana kondisi eksisting fungsi sosial berupa kegiatan rekreasi taman kota di Kota Surakarta?

2. Kegiatan Rekreasi seperti apa yang mempengaruhi intensitas pemanfaatan taman kota di Kota Surakarta?

3. Kesimpulan dan saran dengan keberadaan taman kota di Kota Surakarta?

Tujuan dari penelitian ini adalah untuk mengetahui fungsi sosial baik,dengan temuan ideal atau tidak fungsi sosial yang berkaitan dengan aktivitas rekreasi pengguna terhadap keberadaan taman kota di Kota Surakarta.

\section{ISI PENELITIAN}

\subsection{Metode}

Penelitian deskriptif eksploratif, menganalisis dan menyajikan data secara terstruktur agar mudah dipahami dan disimpulkan. Tujuan untuk menggambarkan keadaan lingkungan sekitar di lokus (taman), tidak dimaksudkan untuk menguji hipotesis tertentu tetapi hanya menggambarkan apa adanya suatu variabel, gejala atau keadaan. 
Dilakukan dengan cara menganalisis fungsi sosial terhadap keberadaan taman kota. dianalisis kegiatan aktivitas yang terjadi di luar dan di dalam taman kota. Penelitian dilakukan untuk mengetahui fungsi sosial yang terjadi untuk menunjukan taman kota yang berkualitas baik dan ideal.

\subsection{Teknik Pengumpulan Data}

Data Primer akan dilakukan dengan observasi adalah pengamatan kualitatif secara langsung oleh peneliti untuk mengambil data-data berdasarkan kondisi di lokasi penelitian. Peneliti mencatat dan mendiskripsikan aktivitas pengguna taman (masyarakat) di dalam dan di luar taman kota.

Data sekunder dilakukan memanfaatkan dokumen yang sudah ada, berupa peraturan pemerintah yang berkaitan dengan ruang terbuka hijau, taman kota dan fungsi sosial. Studi literatur berupa jurnal-jurnal terkait dengan fungsi sosial, rekreasi, taman kota dan ruang terbuka hijau.

\section{Tahapan penelitian:}

Tahapan persiapan penelitian

a. Survey awal, dengan mengenali permasalahan yang ada di lapangan.

b. Pengumpulan data, berupa peta dasar dan data tentang kondisi iklim kota Surakarta.

c. Identifikasi data awal, mengenali data dan menyusun data untuk keperluan kesimpulan awal dan penentuan variabel yang dijadikan pegangan untuk tahap survei kedua untuk melihat temuan di lokasi penelitian.

Tahapan penelitian

Dokumentasi dilakukan untuk mengumpulkan data sekunder yang digunakan untuk melengkapi data primer (observasi/pengukuran) yang telah diperoleh.

Tahapan analisis

a. Tahap identifikasi lapangan dan pengumpulan data.

b. Reduksi data, yaitu sebagai proses seleksi, pemfokusan, pengabstrakan, transformasi data kasar yang ada di lapangan langsung, dan diteruskan pada waktu pengumpulan data.

c. Penyajian data, yaitu rangkaian organisasi informasi yang memungkinkan penelitian dilakukan. Penyajian data diperoleh berbagai jenis, jaringan kerja, keterkaitan kegiatan atau tabel.

d. Penarikan kesimpulan, yaitu dalam pengumpulan data, peneliti harus mengerti dan tanggap terhadap sesuatu yang diteliti langsung di lapangan

\subsection{Gambaran Umum Kota Surakata}

Lokasi penelitian berada di Kota Surakarta, dengan lokasi khusus empat taman kota publik yaitu Taman Monumen 45 (Taman Monjari), Taman Sekartaji di pinggir Sungai Pepe, Taman Tirtonadi di pinggir Sungai Pepe, Taman Balekambang dengan pendekatan fungsi sosial.

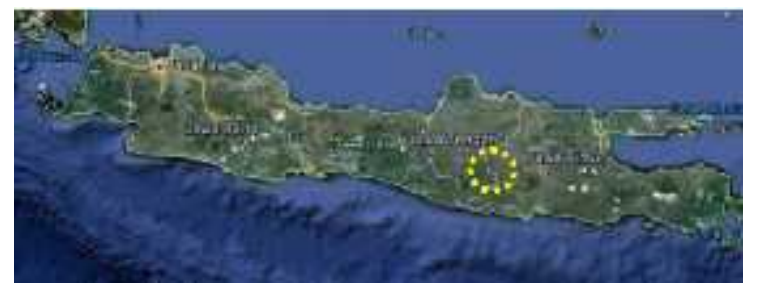

Gambar 1. Peta Pulau Jawa

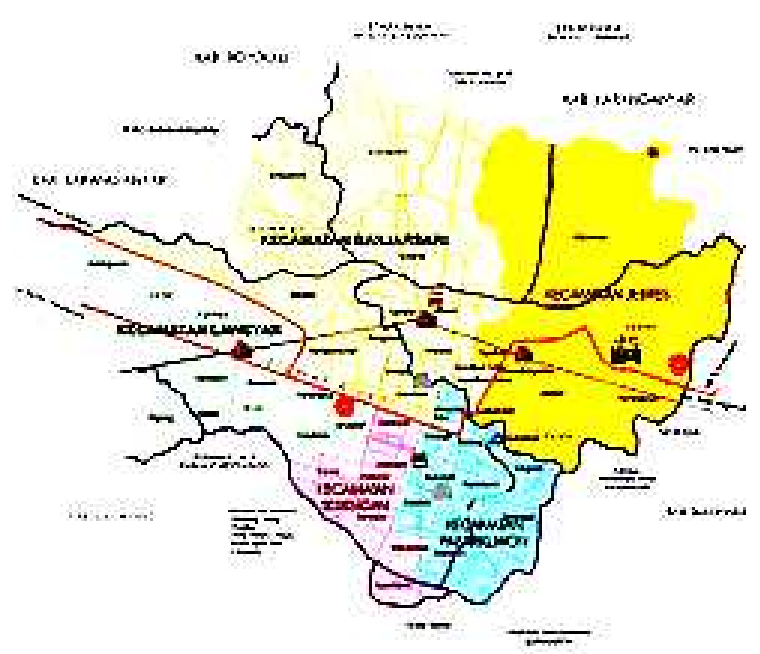

Gambar 2. Peta Surakarta

Surakarta dibagi menjadi 5 kecamatan, yang masingmasing dipimpin oleh seorang camat dan 51 kelurahan yang masing-masing dipimpin oleh seorang lurah. Kelima kecamatan di Surakarta adalah:

- Kecamatan Pasar Kliwon (57110): 9 kelurahan

- Kecamatan Jebres (57120): 11 kelurahan

- Kecamatan Banjarsari (57130): 13 kelurahan

- Kecamatan Laweyan (57140): 11 kelurahan

- Kecamatan Serengan (57150): 7 kelurahan

\subsection{Gambaran Khusus Wilayah Penelitian}

1). Taman Monumen Banjarsari Surakarta

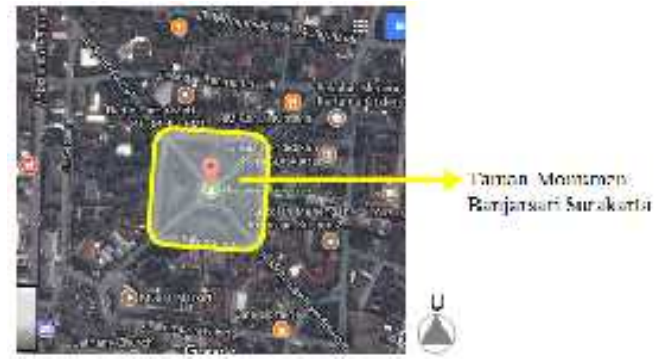

Gambar 3. Taman Monumen Banjarsari

Lokasi taman di Monumen Perjuangan 45 Banjarsari Kota Surakarta, tepatnya di Jl. Monumen 45 Kecamatan Banjarsari. Berada di J1. Monumen 45 dengan batas geografis monumen ini adalah :

Utara : Perumahan

Selatan : Pasar Legi

Barat : Pasar Proliman, Stasiun Balapan

Timur : Sekolah-sekolah

2). Taman Balekambang Surakarta 


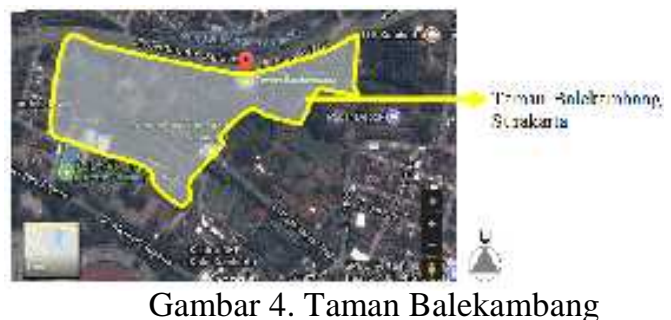

Berada di wilayah Kelurahan Manahan, Kecamatan Banjarsari, Kota Surakarta, dengan batas kawasan : Utara : Jalan Ahmad Yani;

Timur : Pasar Burung dan pemukiman; Selatan : Stadion Olah Raga Manahan, Kolam Tirtomoyo, Kampus FKIP UNS

Barat : Pemukiman Penduduk.

\section{3). Taman Tirtonadi Surakarta}

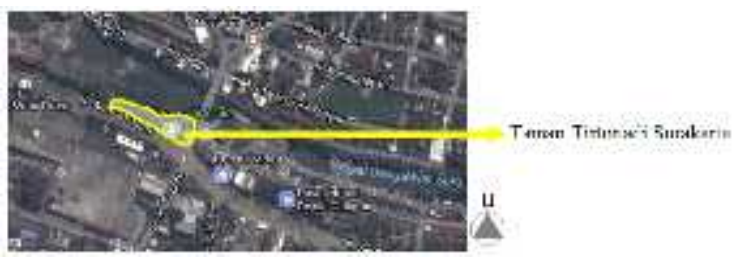

Gambar 5. Taman Tirtonadi

Lokasi Taman yaitu berada di pinggir sungai Bengawan Solo, tepat berada di depan Terminal Tirtonadi di Jalan Ahmad Yani, Kelurahan Gilingan, Kecamatan Banjarsari, Jawa Tengah.

Batas geografis taman ini adalah :

Utara : Sungai Pepe

Selatan : Terminal Tirtonadi

Barat : Sungai Pepe

Timur : Pasar Gilingan

\section{4). Taman Sekartaji Surakarta}

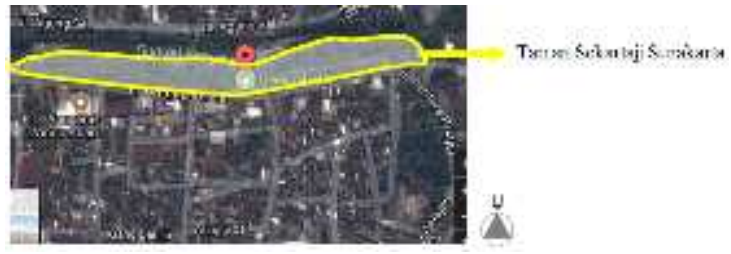

Gambar 6. Taman Sekartaji

Lokasi berada di JL. Kolonel Sutarto, No. 15, Jebres, Solo, Jawa Tengah, Slamet Riyadi, Solo (Surakarta). Taman Sekartaji merupakan salah satu taman kota bantaran sungai di Surakarta yang memanjang dari persimpangan Jalan Tentara Pelajar hingga Pusat Pergudangan Pedaringan. Taman ini digagas oleh Ir. Joko Widodo sebagai Walikota Surakarta sebagai alternatif dalam merubah ruang negatif menjadi ruang positif. Pembangunan taman ini dimulai pada akhir tahun 2009 dan selesai pada tahun 2012

\section{HASIL DAN PEMBAHASAN}

3.1. Tahapan Penelitian Kajian Fungsi Sosial Terhadap Taman Kota di Kota Surakarta
Proses penelitian dilakukan melalui beberapa tahap:

a. Dipilih 4 (empat) lokasi berdasarkan waktu berkumpulnya, kepadatan aktivitas, akses taman di kota.

b. Pengamatan, pencatatan, dokumentasi data selama 5 (lima) hari, Selasa, 5 September sampai dengan Minggu, 10 September 2017. Dilakukan pengamatan kondisi eksisting, sebanyak tiga waktu pengukuran yaitu : pagi (07.00 WIB - 09.00 WIB), siang (12.00-14.00 WIB), dan sore (15.00 - 17.00 WIB). Lokasi taman kota di 4 (empat) taman kota.

c. Mengkaji kondisi lokasi obyek penelitian dengan batasan Taman kota yang bersifat publik dan fungsi sosial. Fungsi sosial berupa kegiatan rekreasi yang terjadi di empat taman kota.

d. Menganalisis kegiatan aktivitas yang terjadi di luar taman atau di dalam taman kota.

\subsection{Fungsi Sosial Terhadap Taman Kota di Kota} Surakarta Taman Monumen Banjarsari

a. Dari hasil pengamatan bahwa fungsi dengan aktivitas rekreasi di Taman Monumen Banjarsari (Monjari) Surakarta ini adalah
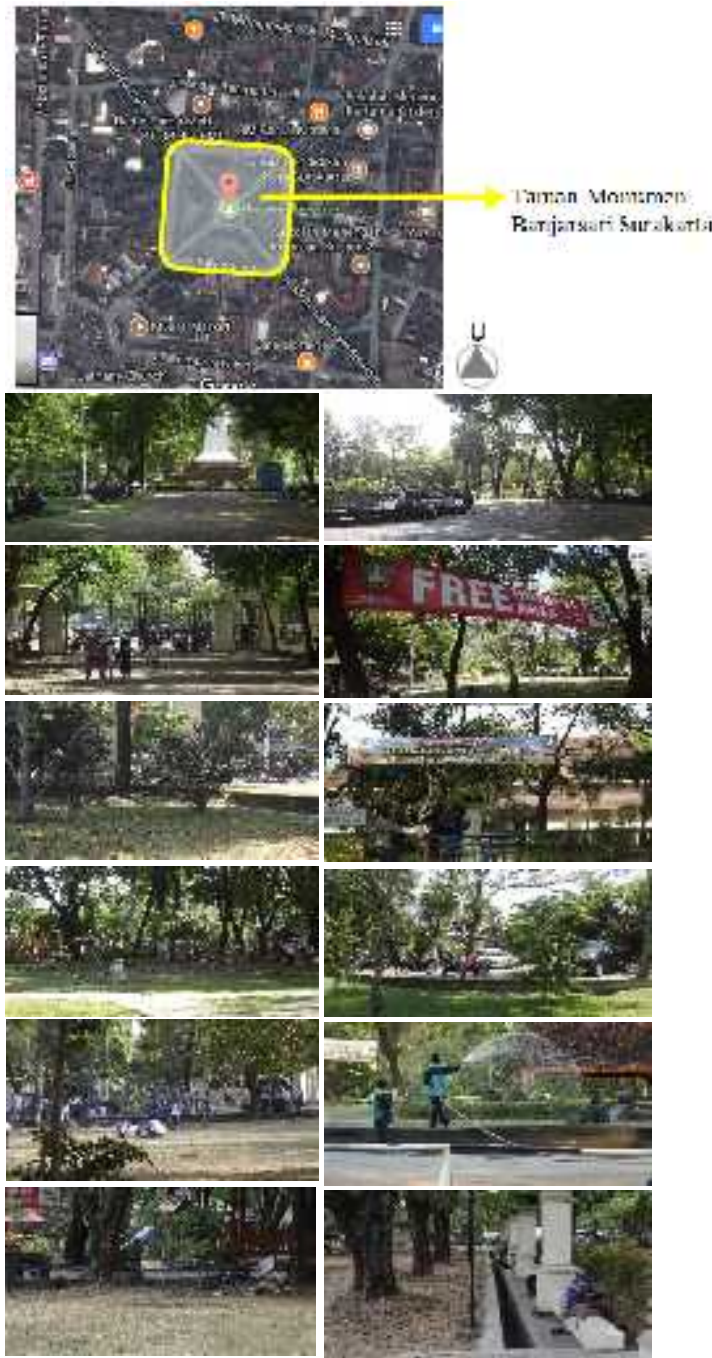


\section{Jurnal Arsitektur, Kota dan Permukiman (LOSARI)}

\begin{tabular}{|c|c|c|c|}
\hline Hams & Foratemt & 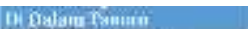 & 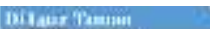 \\
\hline 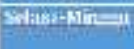 & $\begin{array}{l}0.35-109.00 \\
12.02+2,00\end{array}$ & 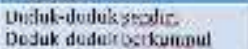 & 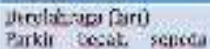 \\
\hline & $15.03-17.00$ & 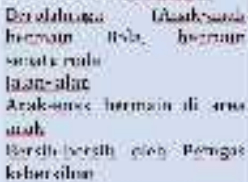 & 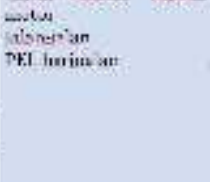 \\
\hline
\end{tabular}

\section{Gambar 7}

Peta Taman, foto kondisi eksisting aktivitas, dan waktu aktivitas di Taman Monumen Banjarsari

b. Dari hasil pengamatan bahwa fungsi dengan aktivitas rekreasi di Taman Balekambang Surakarta ini adalah
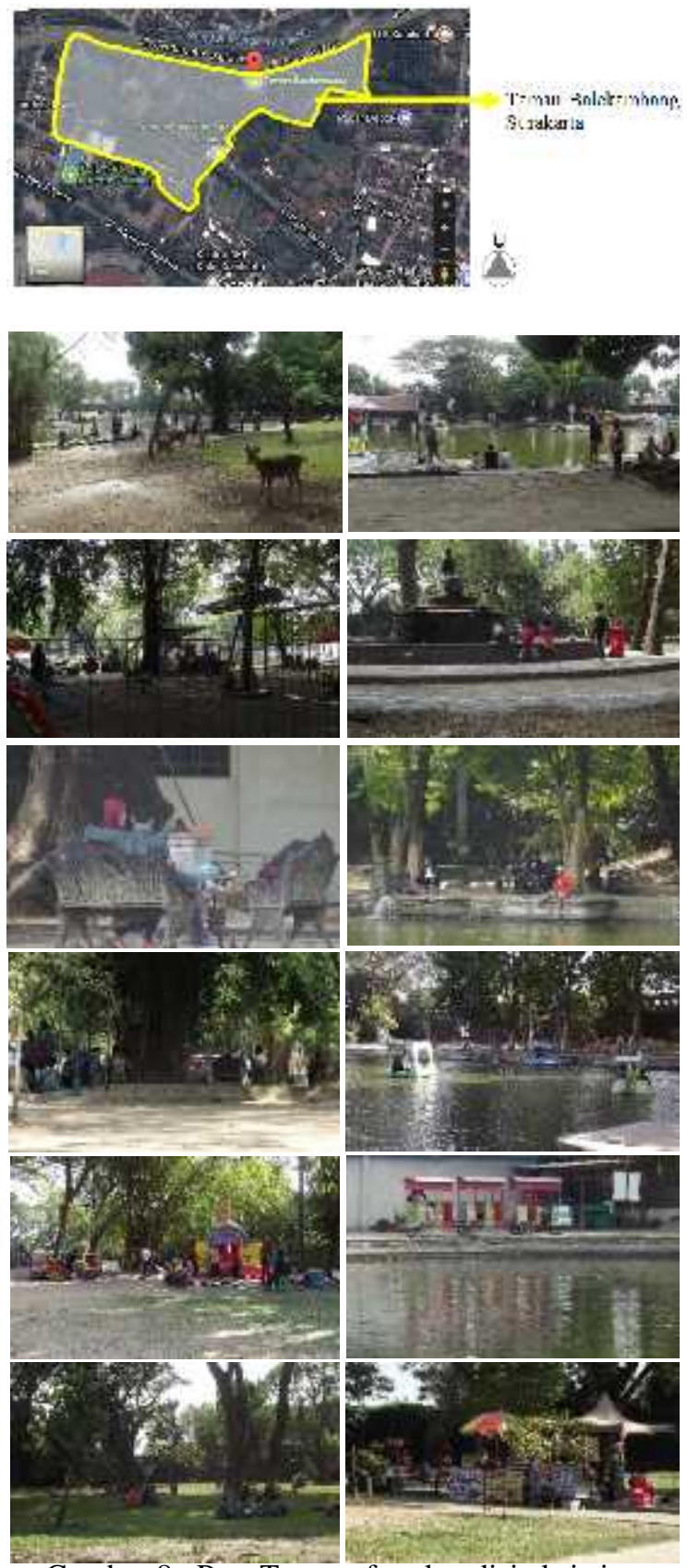

Gambar 8. Peta Taman, foto kondisi eksisting aktivitas dan waktu aktivitas di Taman Balekambang

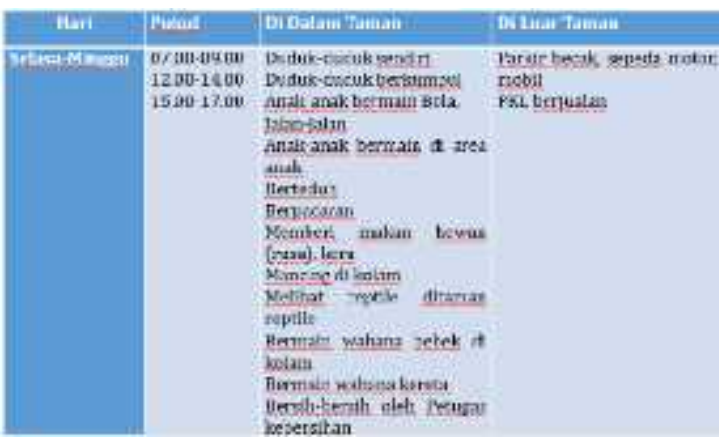

c. Dari hasil pengamatan bahwa fungsi dengan aktivitas rekreasi di Taman Tirtonadi Surakarta ini adalah
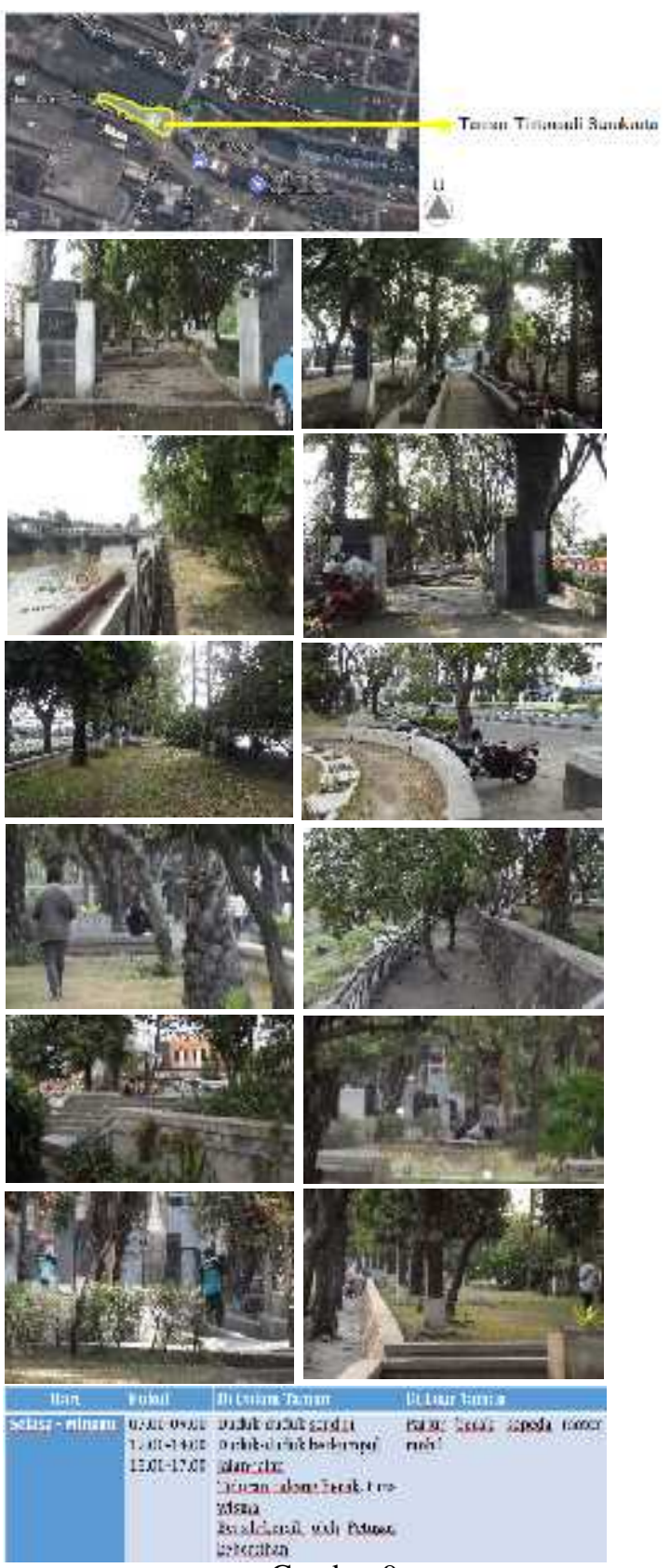

Gambar 9

Peta Taman, foto kondisi eksisting aktivitas dan waktu aktivitas di Taman Titronadi 
d. Dari hasil pengamatan bahwa fungsi dengan aktivitas rekreasi di Taman Sekartaji Surakarta ini adalah

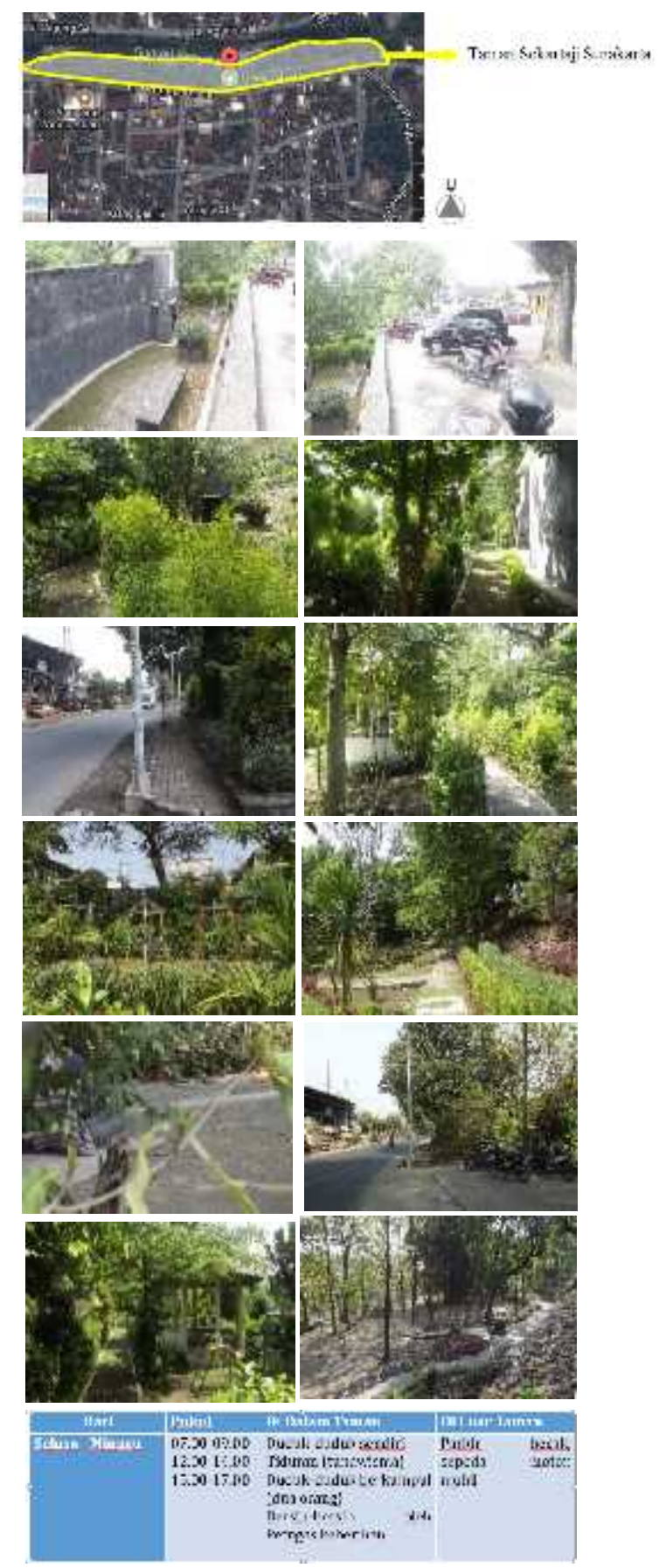

Gambar 10.

Peta Taman, foto kondisi eksisting aktivitas dan waktu aktivitas di Taman Sekartaji

\subsection{Temuan pada 4 (empat) Taman Kota Publik di Kota Surakarta}

Setelah proses analisis fungsi sosial berupa aktivitas rekreasi telah dilakukan, maka muncul temuan pada penelitian di 4 (empat Taman Kota Publik

1. Taman Banjarsari sangat bagus, hal ini ditandai dengan semakin banyaknya warga yang menggunakan taman sebagai ruang terbuka hijau publik. Dan memang pengamatan selama 5 (lima) hari bisa dikatakan taman ini ramai pengunjung dan aktivitasnya hampir sama. Memang lokasi taman ini strategis inilah yang menjadikan taman ini selalu ramai. Tak hanya dikunjungi oleh masyarakat sekitar saja. Taman ini juga biasanya digunakan untuk melepas lelah sejenak. Taman ini tetap terasa sejuk dan nyaman sekali untuk disinggahi. Terutama saat sore hari, taman ini begitu teduh dan cocok sekali. Perawatan terhadap taman ini termasuk baik karena ada petugas perawat taman. Fungsi umum dari taman kota ini banyak sekali yaitu mayoritas untuk berekreasi meliputi; tempat bersantai dan berolahraga, komunikasi sosial.

2. Taman Balekambang sangat bagus, hal ini ditandai dengan semakin banyaknya warga yang menggunakan taman sebagai ruang terbuka hijau publik. Pengamatan selama 5 (lima) hari bisa dikatakan taman ini ramai pengunjung dan aktivitasnya hampir sama. Hari minggu merupakan yang paling banyak dikunjungi dan ramai sekali. Memang lokasi taman ini strategis inilah yang menjadikan taman ini selalu ramai. Tak hanya dikunjungi oleh masyarakat sekitar saja. Taman ini juga biasanya digunakan untuk melepas lelah. Taman ini tetap terasa sejuk dan nyaman sekali untuk disinggahi. Terutama saat sore hari, taman ini begitu teduh dan cocok sekali. Perawatan terhadap taman ini termasuk baik karena ada petugas perawat taman. Fungsi umum dari taman kota ini banyak sekali yaitu mayoritas untuk berekreasi meliputi; tempat bersantai dan berolahraga, komunikasi sosial.

3. Taman Tirtonadi buruk, hal ini ditandai dengan semakin sedikitnya warga yang menggunakan taman sebagai ruang terbuka publik dan jalur pejalan kaki. Sedikitnya pengunjung salah satunya disebabkan oleh beberapa fasiltas taman yang rusak misalnya, akses masuk taman retak, lampu taman hilang, rusak. Perawatan terhadap taman ini sebenarnya termasuk baik karena ada petugas perawat taman. Tidak tersedianya area bermain anak. Dan memang pengamatan selama 5 (lima) hari bisa dikatakan taman ini tidak terlalu sepi pengunjung dan aktivitasnya hampir sama dengan pengunjung rata-rata tunawisma. Namun, pada perkembangannya keberadaan taman-taman kota sebagai ruang publik tersebut mulai tak terawat dan beberapa telah berganti fungsi bahkan hilang.

4. Taman Sekartaji sangat buruk, hal ini ditandai dengan semakin sedikitnya atau sedikit sekali warga yang menggunakan taman sebagai ruang terbuka publik dan jalur pejalan kaki. Perawatan terhadap taman ini sebenarnya termasuk baik karena ada petugas perawat taman. Sepinya pengunjung salah satunya disebabkan oleh beberapa fasilitas taman yang rusak misalnya, 
jembatan penghubung antar zona dalam taman yang berlubang di tengah sehingga tidak bisa diakses, semak belukar yang tumbuh liar menambah kesan negatif pada taman. Sebenarnya tersedia juga area bermain anak tetapi juga tidak digunakan oleh anak-anak. Selama pengamatan selama 5 (lima) hari bisa dikatakan taman ini sepi sekali pengunjung. Perawatan terhadap taman ini sebenarnya termasuk baik karena ada petugas perawat taman.

\section{KESIMPULAN}

Kesimpulan yang didapat yaitu:

1. Taman kota di kota Surakarta yang banyak dikunjungi masyarakat dan aktivitas rekreasinya padat yaitu taman Banjarsari (Monjari), dan Taman Balekambang (termasuk taman kota yang berkualitas baik dan ideal)

2. Taman kota di kota Surakarta tidak terlalu dikunjungi masyarakat atau sedang dan aktivitas rekreasinya tidak padat atau sedang yaitu Taman Tirtonadi. (termasuk taman kota yang berkualitas kurang baik dan kurang ideal)

3. Taman kota di kota Surakarta yang jarang atau sepi dikunjungi masyarakat dan aktivitas rekreasinya sedikit yaitu taman Sekartaji. (termasuk taman kota yang berkualitas tidak baik dan tidak ideal)

\section{SARAN}

Perlu penataan kembali, redesain, perawatan kembali pada taman Sekartaji dan Taman tirtonadi agar tidak terkesan kumuh, kotor, enak dilihat dan dapat menjadi daya tarik bagi masyarakat yang ingin menikmati taman dalam berkegiatan rekreasi. Hal tersebut menjadikan taman kota yang berkualitas baik dan ideal.

\section{DAFTAR PUSTAKA}

Hakim, Rustam. 2007. Komponen Perancangan Arsitektur Lansekap: Prinsip-Unsur dan Aplikasi Desain.Jakarta: Penerbit PT Bumi Aksara.

Rosdiani, Dini. 2015. Pendidikan Rekreasi, Bandung: Alfabeta

Amine Moulay, Norsidah Ujang \& Ismail Said. (2017). Legibility of neighborhood parks as a predicator for enhanced social interaction towards social sustainability. Cities. 61, 58-64.

Andrej Christian Lindholst, Ole Hjorth Caspersen, and Cecil C. Konijnendijk van den Bosch. (2015). Methods for mapping recreational and social values in urban green spaces in the nordic countries and their comparative merits for urban planning. Journal of Outdoor Recreation and Tourism 12.71-81

Jason W. Whiting, Lincoln R. Larson, Gary T. Green \& Chuck Kralowec. (2017). Outdoor recreation motivation and site preferences across diverse racial/ ethnic groups: A case study of Georgia state parks. Journal of Outdoor Recreation and Tourism 18. 10-21

Lindsay K. Campbell, Erika S. Svendsen, Nancy F. Sonti and Michelle L. Johnson. (2015). A social assessment of urban parkland: Analyzing park use and meaning to inform management and resilience planning. Environmental Science \& Policy

Methinee Khotdee, Wichitra Singhirunnusorn, and Nopadon Sahachaisaeree. (2012). Effects of Green Open Space on Social Health and Behaviour of Urban Residents: A Case Study of Communities in Bangkok. Procedia - Social and Behavioral Sciences 36. 449 - 455 